\title{
Correction to: Improving Brain Tumor Diagnosis Using MRI Segmentation Based on Collaboration of Beta Mixture Model and Learning Automata
}

\author{
Akram Edalati-rad ${ }^{1} \cdot$ Mohammad Mosleh $^{1}$
}

Published online: 24 April 2019

(c) King Fahd University of Petroleum \& Minerals 2019

\section{Correction to: \\ Arabian Journal for Science and Engineering https://doi.org/10.1007/s13369-018-3320-1}

"Department of Computer Engineering, Dezful Branch, Islamic Azad University, Dezful, Iran"

In the original publication, the affiliation of the author was published with typo error. The correct affiliation is given below:

The original article can be found online at https://doi.org/10.1007/ s13369-018-3320-1.

\section{Mohammad Mosleh}

Mosleh@iaud.ac.ir

1 Department of Computer Engineering, Dezful Branch, Islamic Azad University, Dezful, Iran 